\title{
Effective Achievement of Hemoglobin Stability with Once-Monthly C.E.R.A. in Peritoneal Dialysis Patients: A Prospective Study
}

\author{
Michael Koch • Wolfgang Treiber • \\ Danilo Fliser
}

Published online: 24 August 2013

(C) The Author(s) 2013. This article is published with open access at Springerlink.com

\begin{abstract}
Background Correction of low hemoglobin ( $\mathrm{Hb})$ levels is associated with improved survival and greater quality of life in dialysis patients, but frequent administration of erythropoiesis stimulating agent (ESA) therapy is unsatisfactory for peritoneal dialysis patients.

Objective The objective of this study was to assess $\mathrm{Hb}$ stability in an unselected population of maintenance peritoneal dialysis patients receiving once-monthly treatment with C.E.R.A., a continuous erythropoietin receptor activator.

Methods In a prospective, non-interventional, single-arm study at 33 Germany dialysis centers, peritoneal dialysis patients with or without ESA treatment prior to study entry received once-monthly treatment with C.E.R.A. Hb stability was assessed by the proportion of patients for whom all measured $\mathrm{Hb}$ values during months 6-8 (the evaluation phase) were within the range $11-12,11-13,10-12$ or $11-12.5 \mathrm{~g} / \mathrm{dL}$.

Results 220 patients received at least one dose of C.E.R.A. During the evaluation phase, 185 patients provided $\geq 1 \mathrm{Hb}$ measurement (efficacy population) and 162 patients provided $\geq 2 \mathrm{Hb}$ measurements (the modified efficacy
\end{abstract}

On behalf of the BEAM study group. The members of the BEAM study group are listed in Appendix.

M. Koch $(\bowtie)$

Nephrology Center, Gartenstrasse 8, 40822 Mettmann, Germany

e-mail: koch@dialyse-mettmann.de

W. Treiber

Renal and Hypertension Center Mittelrhein,

56456 Neuwied, Germany

D. Fliser

Department of Internal Medicine IV, Saarland University, Medical Centre, 66421 Homburg/Saar, Germany population). The mean (SD) time between C.E.R.A. doses was 28.2 (7.2) days and mean (SD) C.E.R.A. dose was 109 (57) $\mu \mathrm{g}$ per application. Mean (SD) Hb level was 11.1 (1.4) $\mathrm{g} / \mathrm{dL}$ at baseline and 11.5 (1.3) $\mathrm{g} / \mathrm{dL}$ at the end of the study (modified efficacy population). The primary efficacy variable, all measured $\mathrm{Hb}$ values in the range $11-12 \mathrm{~g} / \mathrm{dL}$, was $18.4 \%(34 / 185)$ and $14.8 \%(24 / 162)$ in the efficacy and modified efficacy populations, respectively. The mean (SD) maximum intra-individual fluctuation in $\mathrm{Hb}$ level was $0.56(0.50) \mathrm{g} / \mathrm{dL}$ in the efficacy population and 0.58 $(0.49) \mathrm{g} / \mathrm{dL}$ in the modified efficacy population, with maximum intra-individual fluctuation $\leq 1 \mathrm{~g} / \mathrm{dL}$ in $85.4 \%(158 /$ $185)$ and $83.3 \%(135 / 162)$ of patients, respectively. No adverse drug reactions were reported during the study.

Conclusion In this large population of maintenance peritoneal dialysis patients, once-monthly administration of C.E.R.A. achieved a high degree of $\mathrm{Hb}$ stability and was well-tolerated.

\section{Introduction}

Anemia is a well-recognized complication of end-stage renal disease, arising from inadequate production of erythropoietin by the failing kidney in response to declining hemoglobin $(\mathrm{Hb})$ concentration. By the time dialysis is required, approximately three-quarters of patients are anemic [1]. In addition to the classic symptom of fatigue [2], the presence of anemia in patients with peritoneal dialysis contributes to increased cardiovascular risk [3], increased insulin resistance [4] and risk of mortality [5]. An analysis of data from almost 14,000 peritoneally dialyzed patients demonstrated that $\mathrm{Hb}$ levels below $11.0 \mathrm{~g} / \mathrm{dL}$, and particularly levels less than $10 \mathrm{~g} / \mathrm{dL}$, were associated with a higher risk of both hospitalization and mortality [5]. 
Observational evidence that correction of low $\mathrm{Hb}$ levels is associated with improved survival in dialysis patients [6], as well as greater quality of life [7], has led to recommendations that a $\mathrm{Hb}$ level of $11-12 \mathrm{~g} / \mathrm{dL}$ should be targeted in dialysis patients receiving erythropoiesis stimulating agent (ESA) therapy, with the aim of not exceeding $13 \mathrm{~g} / \mathrm{dL}$ [8]. More recently, the Kidney Disease: Improving Global Outcomes (KDIGO) guidelines have proposed that ESA maintenance therapy not be used to maintain $\mathrm{Hb}$ levels above $11.5 \mathrm{~g} / \mathrm{dL}$ in adult patients with CKD, and recommend that ESAs not be used to intentionally increase $\mathrm{Hb}$ above $13.0 \mathrm{~g} / \mathrm{dL}$ [9].

Since the introduction of recombinant human erythropoietin preparations in 1989, the previously widespread problem of severe anemia in end-stage renal disease had been largely overcome. However, such therapies have a relatively short half-life, requiring administration as often as twice or three times a week. For the peritoneal dialysis patient this necessitates regular clinical visits or frequent self-injection at home, which is both unsatisfactory and can affect compliance. Darbepoetin alfa, which has a somewhat longer half-life than epoetin alfa or beta $(\sim 25 \mathrm{~h}[10]$

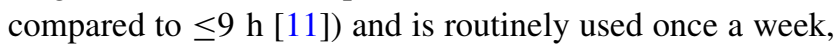
has been assessed for once-monthly dosing in peritoneal dialysis patients in small non-comparative series, but was not always adequate to maintain $\mathrm{Hb}$ levels [12-14].

The pharmacokinetic characteristics of the continuous erythropoietin receptor activator C.E.R.A., including a long half-life $(\sim 130 \mathrm{~h})$, a relatively low binding affinity for the erythropoiesis receptor and low systemic clearance [15], permit once-monthly dosing. The efficacy of once-monthly C.E.R.A. in hemodialysis patients is similar to shorter-acting ESA agents in terms of maintaining Hb levels [16-18]. Clinical experience in hemodialysis patients suggests that conversion from more frequently administered ESA therapies to once-monthly C.E.R.A. is convenient and maintains good control of $\mathrm{Hb}$ levels [19, 20]. Results from the hemodialysis setting, however, are not necessarily applicable to peritoneal dialysis patients. Anemia control with ESA therapy appears to be more readily achieved in peritoneal dialysis patients than in patients receiving hemodialysis [21-25]. A large analysis of US Medicare data from 1995-2000 showed that although ESA therapy was much less frequent in peritoneal dialysis patients (25 versus $80 \%$ of hemodialysis patients), with $50 \%$ lower doses, Hb levels were similar between the two groups [23]. Similarly, a multicenter comparative study in France observed that mean $\mathrm{Hb}$ levels were similar in the peritoneal dialysis or hemodialysis subpopulations but that this was achieved in the peritoneally dialyzed patients with a significantly lower dose of ESA at a lower frequency of administration, and with a reduced rate of intravenous iron therapy [24]. In routine practice, both ESA dose [24-26] and use of intravenous iron
$[24,27]$ is often lower in peritoneal dialysis patients compared to the hemodialysis population. Several factors may be involved in the difference in anemia control between dialysis modalities. Better depuration of erythropoiesis inhibitors during peritoneal dialysis, superior preservation of residual renal function, absence of blood loss from hemodialysis sessions, and greater adequacy of dialysis in terms of frequency and duration may all play a role [28, 29] although their relative contributions are difficult to determine.

The present study was a prospective, multicenter, observational trial undertaken to assess $\mathrm{Hb}$ stability in an unselected population of maintenance peritoneal dialysis patients receiving C.E.R.A. therapy once a month.

\section{Methods}

\subsection{Study Design and Conduct}

This was a prospective, non-interventional, single-arm study conducted at 33 nephrology centers in Germany during the period April 2009 to March 2011. Following enrolment, all patients received C.E.R.A. therapy once a month. The dose of C.E.R.A. was titrated during the first six months post-baseline (the titration phase), with an evaluation phase during the following three months (months 6-8).

The study was undertaken in accordance with German Medicines Act, as a non-interventional study. The observational plan and the informed consent form were approved by the local ethics committee for the lead investigator (MK) (Ärztekammer Nordrhein, Düsseldorf). All study participants provided written informed consent. Roche Pharma AG (Germany) funded the study, including data analysis by a contract research association, and reviewed the manuscript. All data collection was undertaken by the study investigators.

\subsection{Patient Population}

Patients were eligible for inclusion if they were receiving peritoneal dialysis and, in the opinion of the investigator, required ESA therapy. Patients were required to have a life expectancy of more than 9 months and to have iron indices within the limits defined by the European Best Practice Guidelines (serum ferritin $\geq 100 \mathrm{ng} / \mathrm{mL}$ and transferrin saturation $($ TSAT) $\geq 20 \%$ ) [30]. Exclusion criteria comprised active malignancy, acute infection, acute bleeding, decrease in $\mathrm{Hb}$ level within the 4 weeks prior to inclusion (as defined by the investigator), and pregnancy. Patients could be receiving ESA therapy at the time of study entry. Patients were to be withdrawn from the study if an ESA agent other than C.E.R.A. was initiated or if hemodialysis was started. 


\subsection{Medication}

Prior to study entry, any ESA therapy was administered by the physician according to local practice and the summary of product characteristics of the selected ESA. All patients received C.E.R.A therapy from study entry, prescribed according to local practice. Dose changes were made at the discretion of the investigator.

\subsection{Data Collection}

Study visits took place at study entry and then monthly up to nine months after the baseline visit. Assessments took place at routine clinical visits. If a patient discontinued C.E.R.A. prematurely or started hemodialysis, a final assessment was carried out but no further data were documented.

At study entry, the following data were collected: demographics, concomitant disease, cause of end-stage renal disease, duration of peritoneal dialysis, type of previous ESA therapy during the preceding 16 weeks if relevant, use of C.E.R.A. during the preceding 16 weeks, reason for switch to C.E.R.A., current $\mathrm{Hb}$ level prior to C.E.R.A. dose at study entry and laboratory values [iron status, hematology, liver function, estimated glomerular filtration rate (eGFR) calculated by the Modification in Renal Disease (MDRD) formula [31], C-reactive protein, vitamin B12, renal and peritoneal $K t / V$ (where $K$ is dialyzer clearance of urea, $t$ is dialysis time and $V$ is the volume of distribution of urea), parathyroid hormone and albumin]. At all post-baseline study visits, the following data were recorded: Hb level prior to C.E.R.A. administration, laboratory values and changes in concomitant disease/medication. Adverse drug reactions were to be documented, including duration, severity, whether the event was regarded as serious, and causal relationship with C.E.R.A.

Data were recorded by study investigators on printed forms or electronically. Printed data entries were sent directly to an independent clinical research organization (M.A.R.C.O GmbH \& Co KG, 40227 Düsseldorf, Germany), where data were entered to the study database. Electronic data capture contained the same information as the printed forms. The clinical research organization was responsible for clarifying discrepancies on the submitted forms and obtaining additional information from physicians as necessary.

\subsection{Statistical Analysis}

All data are presented descriptively with no formal statistical analyses, as planned in the study protocol. Stability of $\mathrm{Hb}$ was assessed by the proportion of patients for whom all measured $\mathrm{Hb}$ values during months 6-8 (the evaluation phase) were within the range $11-12,11-13,10-12$ or
$11-12.5 \mathrm{~g} / \mathrm{dL}$. The maximum intra-individual fluctuation in $\mathrm{Hb}$ values was defined as the maximum absolute difference from the individual mean $\mathrm{Hb}$ value during the evaluation phase.

The safety population comprised all patients who received at least one dose of C.E.R.A. The efficacy population comprised all patients in the safety population who provided at least one post-baseline measurement of $\mathrm{Hb}$ concentration. The modified efficacy population consisted of all patients in the efficacy population for whom at least two $\mathrm{Hb}$ measurements were available during the evaluation period. A pre-defined subanalysis was performed based on patients in the efficacy population who did not receive C.E.R.A. prior to the study. For patients in whom C.E.R.A. therapy was stopped before the end of the observation period, data were analyzed to the point of discontinuation.

All analyses were descriptive. Statistical analyses were performed using SAS ${ }^{\circledR}$ Version 9.1.3 (SAS Institute, Cary, $\mathrm{NC}, \mathrm{USA}$ )

\section{Results}

\subsection{Patient Population}

A total of 223 patients were enrolled; 220 (98.7\%) received at least one dose of C.E.R.A. and formed the safety population. Of these, 219 patients $(99.5 \%)$ provided at least one post-baseline $\mathrm{Hb}$ measurement and were included in the efficacy population: 185 of these patients provided at least one $\mathrm{Hb}$ measurement during the evaluation phase. The modified efficacy population comprised 162/219 patients (74.0\%) (Fig. 1). The nine-month study was completed by $167 / 220$ patients $(75.9 \%)$, with the most frequent reason for discontinuation being switch to hemodialysis (Fig. 1).

The mean age of the population was approximately 57 years and slightly more than half the patients $(113 / 220$, $51.4 \%$ ) were male (Table 1). Concomitant cardiac disorders and diabetes mellitus type 2 were present in 40.9 and $18.1 \%$ of patients, respectively. At time of study entry, the mean duration of peritoneal dialysis was 3.0 years (range 1-15 years). Most patients (135/220, 61.4\%) were receiving continuous ambulatory peritoneal dialysis (CAPD).

Mean (SD) $\mathrm{Hb}$ at baseline was 11.1 (1.3) g/dL, with a median value of 11.1 (range $5.4-15.7 \mathrm{~g} / \mathrm{dL}$ ) in the safety population. Sixty patients $(27.3 \%)$ were receiving oral iron supplementation and 40 patients $(18.2 \%)$ were receiving intravenous iron; a further four patients $(0.2 \%)$ were receiving unspecified iron preparations. The last postbaseline values for median serum ferritin and TSAT were $114 \mathrm{ng} / \mathrm{mL}(n=160)$ and $26.9 \%(n=146)$, respectively. 
Fig. 1 Patient disposition. C.E.R.A. continuous erythropoietin receptor activator, $H b$ hemoglobin, $E S A$ erythropoiesis stimulating agent

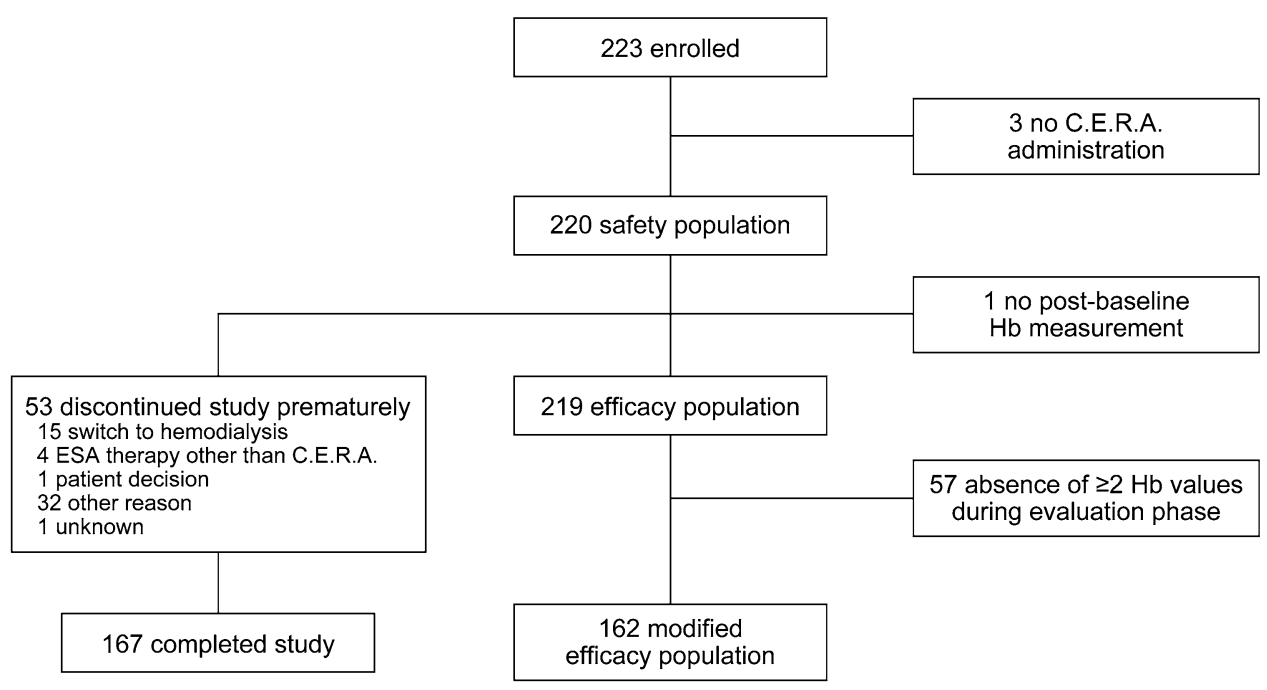

Table 1 Patient characteristics at study entry (safety population, $n=220$ )

\begin{tabular}{ll}
\hline Age (years) & \\
Mean (SD) & $56.9(15.1)$ \\
Median (range) & $113(51.4)$ \\
Male [n (\%)] & \\
Body mass index $\left(\mathrm{kg} / \mathrm{m}^{2}\right)$ & $26.0(4.6)$ \\
Mean (SD) & $25.5(13.7-48.5)$ \\
Median (range) & $215(96.4)$ \\
Caucasian [n (\%)] & \\
Concomitant conditions $[n(\%)]$ & $90(40.9)$ \\
Cardiac disorders & $40(18.2)$ \\
Diabetes mellitus (type 2) & \\
Duration of peritoneal dialysis (years) & $3.0(2.1)$ \\
Mean (SD) & $2.0(1-15)$ \\
Median (range) & \\
Type of peritoneal dialysis $[n(\%)]$ & $135(61.4)$ \\
Continuous ambulatory & $65(29.5)$ \\
Ambulatory & $19(8.6)$ \\
Intermittent & \\
eGFR (mL/min/1.73 m $\left.{ }^{2}\right)$ & $9.9(12.5)$ \\
Mean (SD) & $7.0(1.2-76.5)$ \\
Median (range) & \\
C-reactive protein (mg/L) & $7.2(9.0)$ \\
Mean (SD) & $5.2(0.5-40.0)$ \\
Median (range) & \\
Hb (g/dL) & $11.1(5.4-15.7)$ \\
Mean (SD) & \\
Median (range) & \\
\hline
\end{tabular}

eGFR estimated glomerular filtration rate, $H b$ hemoglobin, $S D$ standard deviation

In the 16 weeks prior to study entry, $75.9 \%$ of patients in the safety population $(167 / 220)$ had received ESA therapy. Of the 106 patients who received previous non-C.E.R.A. ESA therapy, this comprised darbepoetin alfa $[n=72(32.7 \%)]$, epoetin beta $[n=24(10.9 \%)]$, epoetin zeta $[n=15(6.8 \%)]$ and epoetin alfa $[n=11(5.0 \%)]$ (more than one ESA therapy was possible). In total, 61 patients in the safety population received C.E.R.A. prior to study entry. In the modified efficacy population, 47 patients had previously received C.E.R.A.

\subsection{C.E.R.A Administration}

The mean (SD) dose of C.E.R.A. per application was 109 (57) $\mu \mathrm{g}$ throughout the study, equivalent to 3.5 (2.1) $\mu \mathrm{g} /$ day [total cumulative dose $1,040(625) \mu \mathrm{g}$ ]. The most frequent initial doses were $50 \mu \mathrm{g}(38 / 220,17.3 \%), 75 \mu \mathrm{g}$ (48/220, $21.8 \%)$ and $100 \mu \mathrm{g}(43 / 220,19.5 \%)$. The mean dose of C.E.R.A. per application remained stable from baseline [110 (63) $\mu \mathrm{g}]$ to month 9 [103 (61) $\mu \mathrm{g}]$. During the nine-month study period, 138 patients $(62.7 \%)$ required one or more C.E.R.A. dose change, while the remaining 82 patients $(37.3 \%)$ remained on their initial dose. The proportions of patients receiving a dose increase $(106 / 220,48.2 \%)$ or a dose decrease $(111 / 220,50.5 \%)$ were similar, with a mean of 0.9 dose increases and 0.8 dose decreases per patient during the study. In total, the mean (SD) number of dose changes per patient during the study was 1.7 (1.8).

Of the 2,097 C.E.R.A. doses administered during the study, 1,972 $(94.0 \%)$ were given subcutaneously and 92 (4.4\%) intravenously (route was unknown for 33 doses). Doses were administered in the clinic (85/220 patients, $38.6 \%)$, at home $(78 / 220,35.5 \%)$ or both $(57 / 220$, $25.9 \%)$.

The mean (SD) time between C.E.R.A. doses was 28.2 (7.2) days. 


\subsection{Efficacy}

Mean (SD) Hb level was 11.1 (1.4) g/dL at baseline and $11.5(1.3) \mathrm{g} / \mathrm{dL}$ at the end of the study (modified efficacy population) (Fig. 2). A small initial rise after study entry was attributed to the 53 patients who were not previously receiving ESA therapy prior to study, in whom mean (SD) $\mathrm{Hb}$ increased from $11.0(1.4) \mathrm{g} / \mathrm{dL}$ at baseline to 11.5 (1.4) $\mathrm{g} / \mathrm{dL}$ one month after initiation of C.E.R.A. therapy and $11.3(1.5) \mathrm{g} / \mathrm{dL}$ at month 9. For the 106 patients who were receiving non-C.E.R.A. ESA treatment prior to the study, mean (SD) Hb level was 11.3 (1.3) g/dL at baseline, $11.5(1.2) \mathrm{g} / \mathrm{dL}$ after one month and $11.7(1.0) \mathrm{g} / \mathrm{dL}$ at month 9 .

Figure 3 illustrates the proportion of patients with all available $\mathrm{Hb}$ values within pre-specified ranges during the evaluation phase. The proportion of patients in the range $11-12 \mathrm{~g} / \mathrm{dL}$ during the evaluation phase, i.e. the primary efficacy variable, was $18.4 \%(34 / 185)$ of patients in the efficacy population for whom $\mathrm{Hb}$ measurements were provided, and $14.8 \%$ (24/162) in the modified efficacy population. During the evaluation phase, approximately $40 \%$ of patients in the efficacy and the modified efficacy populations had all measured $\mathrm{Hb}$ levels within the 10-12 or $11-13 \mathrm{~g} / \mathrm{dL}$ ranges (Fig. 3). Among the 115 patients in the modified efficacy population who did not receive C.E.R.A. prior to study entry, $13.9 \%$ (16/115), $38.3 \%$ (44/115) and $38.3 \%$ (44/115) had all $\mathrm{Hb}$ values within the ranges 11-12, $10-12$ and $11-13 \mathrm{~g} / \mathrm{dL}$, respectively. During the evaluation period, approximately $83 \%$ of patients had all $\mathrm{Hb}$ values $\geq 10 \mathrm{~g} / \mathrm{dL}$ and $87 \%$ of patients had all Hb values $\leq 13 \mathrm{~g} / \mathrm{dL}$ in both the efficacy and modified efficacy populations (Fig. 3).

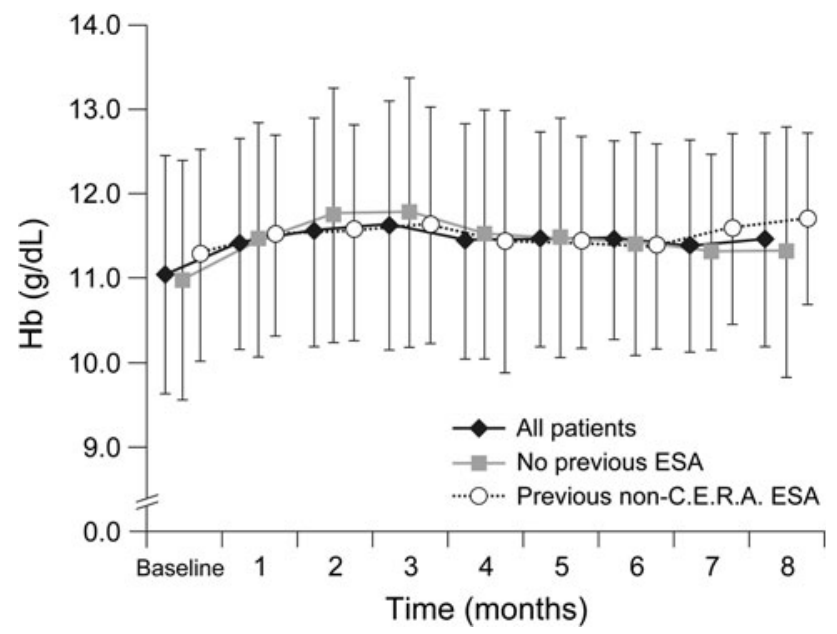

Fig. 2 Mean (SD) hemoglobin level in all patients, in patients without any erythropoiesis stimulating agent (ESA) therapy prior to study entry, and in patients who received an ESA therapy other than continuous erythropoietin receptor activator (C.E.R.A.) prior to study entry (modified efficacy population, $n=162$ )

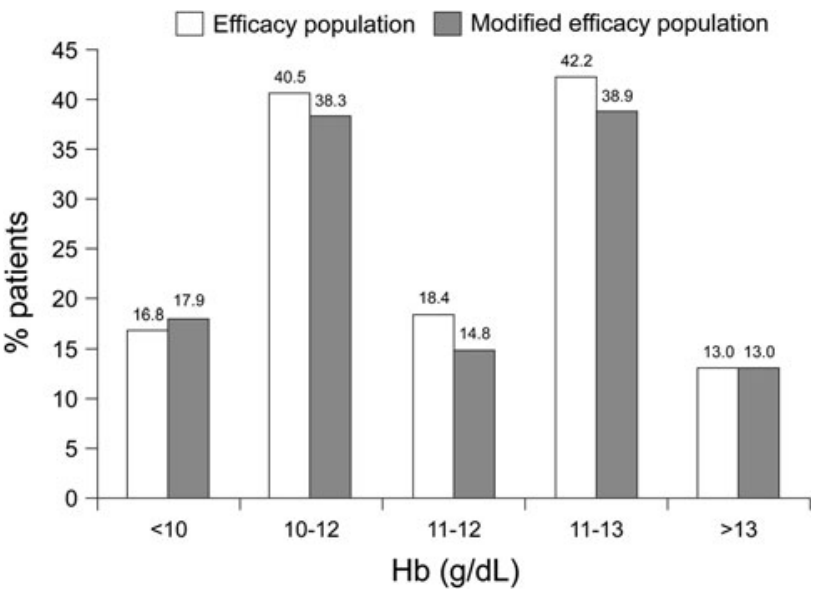

Fig. 3 Proportion of patients within pre-specified hemoglobin $(\mathrm{Hb})$ ranges during the evaluation phase (months 6-8). The efficacy population consisted of patients with at least one $\mathrm{Hb}$ value during the evaluation phase $(n=185)$. The modified efficacy population consisted of all patients in the efficacy population for whom at least two $\mathrm{Hb}$ measurements were available during the evaluation period $(n=162)$

The mean (SD) maximum intra-individual fluctuation in $\mathrm{Hb}$ level during the evaluation period was 0.56 $(0.50) \mathrm{g} / \mathrm{dL}$ in the efficacy population and $0.58(0.49) \mathrm{g} / \mathrm{dL}$ in the modified efficacy population. The maximum intraindividual fluctuation during the evaluation phase was $\leq 1 \mathrm{~g} / \mathrm{dL}$ in $85.4 \%(158 / 185)$ and $83.3 \%(135 / 162)$ of patients in the efficacy and modified efficacy populations, respectively.

\subsection{Safety and Tolerability}

No adverse drug reactions were reported during the study. No clinically relevant changes in laboratory values or vital signs were noted during the study.

\section{Discussion}

In this large population of maintenance peritoneal dialysis patients, once-monthly administration of C.E.R.A. achieved a high degree of $\mathrm{Hb}$ stability and was well-tolerated when administered according to local practice. Conversion from more frequently-administered ESA therapies to C.E.R.A.—or introduction of C.E.R.A. as de novo therapy-proved convenient, with relatively few doses changes and approximately $65 \%$ of patients administering at least one dose at home.

Maintaining $\mathrm{Hb}$ levels within a narrow target range in dialysis patients is notoriously challenging due to the high degree of $\mathrm{Hb}$ variability observed in dialysis populations [32]. Indeed, one retrospective study in the 
Netherlands, which included 56 hemodialysis patients and 12 peritoneal dialysis patients, found that none remained within the target range of $11-12 \mathrm{~g} / \mathrm{dL}$ over a one-year period during ESA therapy [33]. The current real-life population is likely to have included more challenging patients than in randomized controlled trials which, for example, frequently specify a baseline $\mathrm{Hb}$ range and maximum limits for $\mathrm{Hb}$ fluctuation as part of the inclusion criteria. Against this background, the finding that only approximately $15 \%$ of patients in the modified efficacy population achieved the primary variable of all $\mathrm{Hb}$ levels within 11-12 $\mathrm{g} / \mathrm{dL}$ during the threemonth evaluation phase is not unexpected. Perhaps more relevantly, few patients had $\mathrm{Hb}$ values $<10 \mathrm{~g} / \mathrm{dL}$ (approximately $17 \%$ ). Importantly, only $13 \%$ had a single $\mathrm{Hb}$ value above $13 \mathrm{~g} / \mathrm{dL}$ during the evaluation period, consistent with recent recommendations from KDIGO [9].

The initial doses of C.E.R.A prescribed by the managing physicians were appropriate, as indicated by the largely unchanged mean dose and the similar proportion of dose increases and dose decreases during the study. Multicenter studies in which hemodialysis patients were converted from shorter-acting ESA preparations to monthly C.E.R.A. have reported similar findings [20,34]. It is encouraging that almost $40 \%$ of patients required no dose changes over the 9-month study, with an overall mean of fewer than two dose changes per patient. This is consistent with findings from a pooled analysis of three comparative Phase III trials of C.E.R.A. twice- or once-monthly versus shorter-acting ESAs in hemodialysis patients, in which significantly fewer dose changes were required in the C.E.R.A. treated patients [35], and previous observational data in peritoneally dialyzed patients [36]. More frequent ESA dose changes show an association with increased $\mathrm{Hb}$ fluctuation [33, 36], a relationship that appears to be causal [36], so a low rate of dose alterations may support stable $\mathrm{Hb}$ control. Data from dialysis populations $[37,38]$ have suggested that fluctuation from target $\mathrm{Hb}$ range to values below $11 \mathrm{~g} / \mathrm{dL}$ are associated with increased mortality. Here, the mean fluctuation in $\mathrm{Hb}$ levels over the nine-month study was $\sim 1.5 \mathrm{~g} / \mathrm{dL}$, which compares favorably with published data [33]. A retrospective, single-center analysis reported a trend to fewer excursions from $\mathrm{Hb}$ target range in C.E.R.A.-treated peritoneal dialysis patients versus those receiving epoetin beta, although complete $\mathrm{Hb}$ cycles were similar in both groups [36]. The authors concluded that fewer dose changes with C.E.R.A. may offer a small advantage in reducing the degree of $\mathrm{Hb}$ variability [36].
Another 9-month observational study with a similar protocol has been conducted in 924 hemodialysis patients [20]. Baseline $\mathrm{Hb}$ levels were broadly similar to the current population [mean (SD) $11.4(1.2) \mathrm{g} / \mathrm{dL}$ compared to 11.1 (1.3) $\mathrm{g} / \mathrm{dL}$ here] [20]. During the evaluation phase in the hemodialysis patients, $\mathrm{Hb}$ parameters were consistently similar to those seen in the current peritoneal dialysis population, including mean $\mathrm{Hb}$ levels, the proportion of patients within pre-specified $\mathrm{Hb}$ ranges, the mean intraindividual $\mathrm{Hb}$ fluctuation and the proportion of patients with a maximum intra-individual fluctuation $\leq 1 \mathrm{~g} / \mathrm{dL}$. In the hemodialysis patients, however, the mean dose of C.E.R.A. over the nine-month study was $124 \mu \mathrm{g}$ compared to $109 \mu \mathrm{g}$ in the current peritoneal dialysis population. Carrera et al. [39] described an initial mean C.E.R.A. dose of $159 \mu \mathrm{g}$, titrated upwards by protocol to $260 \mu \mathrm{g}$. These data are in line with published data showing that higher ESA doses are often required in hemodialysis patients to achieve the same level of $\mathrm{Hb}$ control as in peritoneally dialyzed patients [21-25].

With regards the safety profile of C.E.R.A., no adverse drug reaction was reported in this series of over 200 patients during the eight-month period.

\section{Conclusions}

Once-monthly C.E.R.A. was effective and well-tolerated when used in routine clinical practice for the treatment of anemia in peritoneal dialysis patients either following conversion from more frequently-dosed ESA therapies or as de novo treatment. Results in this largely unselected population of peritoneally dialyzed patients suggest that the effectiveness of once-monthly C.E.R.A. in peritoneally dialyzed patients is similar to that observed in hemodialysis patients but that this may be achieved at a slightly lower dose.

Acknowledgments With grateful thanks to the study investigators (see Appendix).

Disclosures Author contributions: All authors contributed to the study design, collected clinical data, evaluated the data, critically assessed the manuscript and gave final approval for submission.

Funding: The study was supported by Roche Pharma AG, Germany. A freelance medical writer assisted in the development of the manuscript with funding from Roche Pharma AG.

Conflict of interest MK and WT have no conflicts of interest to declare. DF has received consulting and speaker's honoraria from Amgen, Roche Pharma AG and Ortho Biotech.

Open Access This article is distributed under the terms of the Creative Commons Attribution Noncommercial License which permits any noncommercial use, distribution, and reproduction in any medium, provided the original author(s) and the source are credited. 


\section{Appendix: The BEAM Study Investigators}

All locations are in Germany.

Samih Al-Sarraf, Augsburg; Volker Becker, Heusenstamm; Lucia Bittorf-Rollenhagen, Berlin; Gunnar Bücker, Osnabrück; Theo Busch, Moers; Ernst-Gerhard Dannemann, Gelsenkirchen; Tilman David-Walek, Kiel; Ralf Desselberger, Greifswald; Robert Dunst, Reut-lingen; Hans-Herbert Echterhoff, Bielefeld; Danilo Fliser, Homburg; Björn Friedrich, Leonberg; Christian Friedrichsohn, Villingen-Schwennigen; Klaus Fromm-herz, St. Wendel; Georg Georges, Tübingen; Gerd Hetzel, Düssel-dorf; Martin Kimmel \& Niko Braun, Stuttgart; Rüdiger Knaup, Siegen; Michael Koch, Mettmann; Axel Krieter, München; Heike Martin, Zwickau; Uta Neuhäuser-Piduhn, Dortmund; Rainer Nowack, Lindau; Susanne Pawlow-Handt \& Manfred Schlöcker, Wolfenbüttel; Sylvia Petersen, Berlin; Jörg Radermacher, Minden; Andreas Raffelsiefer, Warendorf; Thomas Rath, Kai-serslautern; Peter Rawer, Wetzlar; Manfred Schmitt, Speyer; Frank Seibt \& Erika Eger, Berlin; Wolfgang Treiber \& Thomas Sures, Neuwied; Sibille Tröster, Westerstede; Volker Vielhauer, München.

\section{References}

1. McClellan W, Aronoff SL, Bolton WK, et al. The prevalence of anemia in patients with chronic kidney disease. Curr Med Res Opin. 2004;20:1501-10.

2. Ossareh S, Roozbeh J, Krishnan M, Liakopoulos V, Bargman JM, Oreopoulos DG. Fatigue in chronic dialysis patients. Int Urol Nephrol. 2003;35:535-41.

3. García-López E, Carrero JJ, Suliman ME, Lindholm B, Stenvinkel P. Risk factors for cardiovascular disease in patients undergoing peritoneal dialysis. Perit Dial Int. 2007;27(Suppl 2):S205-9.

4. Fortes PC, de Moraes TP, Mendes JG, Stinghen AE, Ribeiro SC, Pecoits-Filho R. Insulin resistance and glucose homeostasis in peritoneal dialysis. Perit Dial Int. 2009;29(Suppl 2):S145-8.

5. Li S, Foley RN, Collins AJ. Anemia, hospitalization, and mortality in patients receiving peritoneal dialysis in the United States. Kidney Int. 2004;65:1864-9.

6. Locatelli F, Pisoni RL, Combe C, et al. Anaemia in five European countries: association with morbidity and mortality in the Dialysis Outcomes and Practice Patterns Study (DOPPS). Nephrol Dial Transplant. 2004;19:121-32.

7. Valderrábano F. Quality of life benefits of early anaemia treatment. Nephrol Dial Transplant. 2000;15(Suppl 3):23-8.

8. Locatelli F, Covic A, Eckardt KU, Wiecek A, Vanholder R, ERA-EDTA ERBP Advisory Board. Anaemia management in patients with chronic kidney disease: a position statement by the Anaemia Working Group of European Renal Best Practice (ERBP). Nephrol Dial Transplant. 2009;24:348-54.

9. Kidney Disease: Improving Global Outcomes (KDIGO) Anemia Work Group. KDIGO Clinical Practice Guideline for Anemia in Chronic Kidney Disease. Kidney Int Suppl. 2012;2:279-335.

10. Macdougall IC, Gray SJ, Elston O, et al. Pharmacokinetics of novel erythropoiesis stimulating protein compared with epoetin alfa in dialysis patients. J Am Soc Nephrol. 1999;10:2392-5.
11. Halstenson CE, Macres M, Katz SA, et al. Comparative pharmacokinetics and pharmacodynamics of epoetin beta. Clin Pharmacol Ther. 1991;50:702-12.

12. Suzuki H, Inoue T, Watanabe $\mathrm{Y}$, et al. Testing a single monthly dose of darbepoetin alpha to maintain hemoglobin levels in continuous ambulatory peritoneal dialysis patients. Adv Perit Dial. 2011;27:60-4.

13. Theodoridis M, Passadakis P, Kriki P, et al. Efficient monthly subcutaneous administration of darbepoetin in stable CAPD patients. Perit Dial Int. 2005;25:564-9.

14. Hiramatsu M, Kubota M, Iwaksi M, Panagoutsos S, Yannatos E, Kantartzi K, KRN321 A09 Study Group. Darbepoetin alfa (KRN321) administered intravenously once monthly maintains hemoglobin levels in peritoneal dialysis patients. Ther Apher Dial. 2008;12:19-27.

15. Macdougall IC, Robson R, Opatrna S, et al. Pharmacokinetics and pharmacodynamics of intravenous and subcutaneous continuous erythropoietin receptor activator (C.E.R.A.) in patients with chronic kidney disease. Clin J Am Soc Nephrol. 2006;1:1211-5.

16. Locatelli F, Villa G, de Francisco ALM, on behalf of the BA16286 Study Investigators, et al. Effect of a continuous erythropoietin receptor activator (C.E.R.A.) on stable haemoglobin in patients with CKD on dialysis: once monthly administration. Curr Med Res Opin. 2007;23:969-79.

17. Levin NW, Fishbane S, Cañedo FV, MAXIMA Study Investigators, et al. Intravenous methoxy polyethylene glycol-epoetin beta for haemoglobin control in patients with chronic kidney disease who are on dialysis: a randomised non-inferiority trial (MAXIMA). Lancet. 2007;370:1415-21.

18. Sulowicz W, Locatelli F, Ryckelynck JP, PROTOS Study Investigators, et al. Once-monthly subcutaneous C.E.R.A. maintains stable hemoglobin control in patients with chronic kidney disease on dialysis converted directly from epoetin one to three times weekly. Clin J Am Soc Nephrol. 2007;2:637-46.

19. Fliser D, Kleophas W, Dellanna F, et al. Evaluation of maintenance of stable haemoglobin levels in haemodialysis patients converting from epoetin or darbepoetin to monthly intravenous C.E.R.A.: the MIRACEL study. Curr Med Res Opin. 2010; 26:1083-9.

20. Weinreich T, Leistikow F, Hartmann HG, Vollgraf G, Dellanna F, the SESAM Study Group. Monthly continuous erythropoietin receptor activator treatment maintains stable hemoglobin levels in routine clinical management of hemodialysis patients. Hemodial Int. 2012;16:11-9.

21. Stegmayr BG. Better response to s.c. erythropoietin in CAPD than HD patients. Scand J Urol Nephrol. 1997;31:183-7.

22. Sieniawska M, Roszkowska-Blaim M. Recombinant human erythropoietin dosage in children undergoing hemodialysis and continuous ambulatory peritoneal dialysis. Pediatr Nephrol. 1997;11:628-30.

23. Snyder JJ, Foley RN, Gilbertson DT, Vonesh EF, Collins AJ. Hemoglobin levels and erythropoietin doses in hemodialysis and peritoneal dialysis patients in the United States. J Am Soc Nephrol. 2004;15:174-9.

24. Coronel F, Herrero JA, Montenegro J, et al. Erythropoietin requirements: a comparative multicenter study between peritoneal dialysis and hemodialysis. J Nephrol. 2003;16:697-702.

25. Richardson D, Ford D, Gilg J, Williams A. UK Renal Registry 12th Annual Report (December 2009): chapter 9: anaemia variables in UK adult dialysis patients in 2008: national and centrespecific analyses. Nephrol Clin Pract. 2010;115(Suppl 1): c153-86.

26. Soffritti S, Russo G, Cantelli S, Gilli G, Catizone L. Maintaining over time clinical performance targets on anaemia correction in unselected population on chronic dialysis at 20 Italian centres. 
Data from a retrospective study for a clinical audit. BMC Nephrol. 2009;10:33.

27. St Peter WL, Obrador GT, Roberts TL, Collins AJ. Trends in intravenous iron use among dialysis patients in the United States (1994-2002). Am J Kidney Dis. 2005;46:650-60.

28. Locatelli F, Del Vecchio L, Andrulli S. The modality of dialysis treatment: does it influence the response to erythropoietin treatment? Nephrol Dial Transplant. 2001;16:1971-4.

29. House AA, Pham B, Pagé DE. Transfusion and recombinant human erythropoietin requirements differ between dialysis modalities. Nephrol Dial Transplant. 1998;13:1763-9.

30. Locatelli F, Aljama P, Bárány P, European Best Practice Guidelines Working Group, et al. Revised European best practice guidelines for the management of anaemia in patients with chronic renal failure. Nephrol Dial Transplant. 2004;19(Suppl 2):ii1-47.

31. Levey AS, Coresh J, Greene T, et al. Expressing the modification of diet in renal disease study equation for estimating glomerular filtration rate with standardized serum creatinine values. Clin Chem. 2007;53:766-72.

32. Fishbane S, Berns JS. Hemoglobin cycling in hemodialysis patients treated with recombinant human erythropoietin. Kidney Int. 2005;68:1337-43.

33. van der Putten K, van der Baan FH, Schellekens H, Gaillard CA. Hemoglobin variability in patients with chronic kidney disease in the Netherlands. Int J Artif Organs. 2009;32:787-93.
34. Dellanna F, Winkler RE, Bozkurt F, MIRACEL Study Group, et al. Dosing strategies for conversion of haemodialysis patients from short-acting erythropoiesis stimulating agents to oncemonthly C.E.R.A.: experience from the MIRACEL study. Int $\mathbf{J}$ Clin Pract. 2011;65:64-72.

35. Mann JF, de Francisco A, Nassar G, Canaud B. Fewer dose changes with once-monthly C.E.R.A. in patients with chronic kidney disease. Clin Nephrol. 2011;76:9-15.

36. Selby NM, Fonseca SA, Fluck RJ, Taal MW. Hemoglobin variability with epoetin beta and continuous erythropoiesis receptor activator in patients on peritoneal dialysis. Perit Dial Int. 2012; 32:177-82.

37. Roche A, Macdougall IC, Walker RG. Hemoglobin fluctuations in patients on haemodialysis treated with ESAs: clinical observations from two centres. Curr Med Res Opin. 2009;25:2971-6.

38. Gilbertson DT, Ebben JP, Foley RN, Weinhandl ED, Bradbury $\mathrm{BD}$, Collins AJ. Hemoglobin level variability: associations with mortality. Clin J Am Soc Nephrol. 2008;3:133-8.

39. Carrera F, Lok CE, de Francisco A, et al. Maintenance treatment of renal anaemia in haemodialysis patients with methoxy polyethylene glycol-epoetin beta versus darbepoetin alfa administered monthly: a randomized comparative trial. Nephrol Dial Transplant. 2010;25:4009-17. 